Nilsen, E. S., Silva, J., McAuley, T. \& Floto, S. (2020). Executive functioning moderates associations between shyness and pragmatic language. Social Development, 30(2), 554-574. https://doi.org/10.1111/sode.12485

\title{
Executive Functioning Moderates Associations Between Shyness and Pragmatic Abilities
}

\begin{abstract}
While elevated shyness is associated with weaker pragmatic language abilities for some children, not all shy children demonstrate pragmatic challenges. Understanding the factors that may account for this variability is important as proficient pragmatic abilities have been found to protect shy children from subsequent socio-emotional maladjustment (Coplan \& Weeks, 2009). Individual differences in cognitive processes may account for why some shy children evidence difficulty in pragmatic abilities whereas others do not. In the current study, associations between shyness, executive functioning (performance-based and parent-reported), and pragmatic abilities (knowledge and demonstrated abilities) were examined in a community sample of 8-12 year old children $(N=81)$. Consistent with past work, shyness was associated with weaker pragmatic knowledge. However, parent-reported executive functioning moderated associations between shyness and both pragmatic knowledge and demonstrated pragmatic abilities in everyday activities. Only those shy children with weaker parent-reported executive functioning showed difficulties in their pragmatic abilities. That is, strength in applying executive functioning in everyday settings (or less executive $d y$ sfunction) seems to buffer shy children from pragmatic challenges. We discuss our results in terms of the way children acquire pragmatic competence and the temperamental and cognitive factors that may affect such development.
\end{abstract}

Keywords: communication; pragmatic language; shyness; executive functioning; language; temperament

This is the peer reviewed version of the following article: Nilsen, E. S., Silva, J., McAuley, T. \& Floto, S. (2020). Executive functioning moderates associations between shyness and pragmatic language. Social Development, 30(2), 554-574. https:// doi.org/10.1111/sode.12485, which has been published in final form at https://doi.org/10.1111/sode.12485. This article may be used for non-commercial purposes in accordance with Wiley Terms and Conditions for Use of Self-Archived Versions. 


\section{Executive Functioning Moderates Associations Between Shyness and Pragmatic Abilities}

Effective communication skills allow children to be successful in their interactions with others. One important aspect of communication, pragmatic abilities, is the skill to use language that incorporates contextual and social cues to engage with others (Matthews, Biney, \& AbbotSmith, 2018). There are a number of factors associated with variability in children's pragmatic abilities. Specific to the present work, children who exhibit high levels of shyness demonstrate less proficiency than their non-shy peers in pragmatic abilities (Coplan \& Weeks, 2009). However, not all shy children exhibit such challenges and, further, such variance in pragmatic abilities predicts shy children's socio-emotional maladjustment (Coplan \& Armer, 2005; Coplan \& Weeks, 2009). Thus, identifying factors that influence the associations between shyness and pragmatic abilities is important. Drawing from work highlighting the importance of cognitive skills for pragmatic abilities (Nilsen \& Fecica, 2011), the present work examined the extent to which children's executive functioning moderated associations between shyness and pragmatic abilities. These patterns were examined within two aspects of pragmatic abilities, namely, pragmatic knowledge (i.e., knowing what to say in a situation) and demonstrated pragmatic ability (i.e., parent's observations of pragmatic abilities in everyday interactions).

We explored these research goals within a school-age group of children. We chose this age range as it is a time when more complex aspects of pragmatic abilities develop (Airenti, 2017) and when a child's ability to interact successfully with others becomes particularly important for their well-being (Parker, Rubin, Erath, Wojslawowicz, \& Buskirk, 2006). Moreover, the school-age years are a time when children's levels of shyness and selfconsciousness are more stable than at earlier points in development (Karevold, Ystrom, Coplan, Sanson, \& Mathiesen, 2012). 


\section{Pragmatic Abilities}

While there is variability (and difficulty) in defining pragmatic abilities (Ariel, 2000; Levinson, 1983), this multifaceted construct refers to appropriately and effectively using language in context to engage with others. There are a number of specific abilities that fall under the umbrella term of 'pragmatics', including (but not limited to), the ability to engage in conversation, generating utterances that contain relevant, non-redundant, and appropriatelydetailed information (for the context and a listener), the use of context and social cues to interpret language, and using appropriate tone and language for a listener. Earliest evidence of pragmatic development (at 9- to 10-months of age) include gestures and vocalizations that serve pragmatic functions such as requesting, labeling, protesting, and greeting (Bates, Camaioni, \& Volterra, 1975; Dale, 1980). By 2-years-old, children demonstrate a multitude of pragmatic acts (e.g., asking questions, negotiating, discussing) and during the preschool years children show rapid growth and increased sophistication in their abilities (Ninio \& Snow, 1996; O’Neill, 2007). Throughout their school-age years, children demonstrate an increased ability to tailor their language to a conversational partner (e.g., Clark, 2003; Nilsen \& Graham, 2009; Lloyd, Mann, \& Peers, 1998), adhere to conversational rules (Ackerman, 1981), use contextual and social cues to understand and produce non-literal language (Filippova \& Astington, 2008; Harris \& Pexman, 2003), and adhere to norms of politeness, such as using white lies (Talwar, Murphy, \& Lee, 2007). Thus, while many aspects of pragmatic abilities start early in life, it is only within the school-age years that children start to show a more fulsome comprehension and demonstration of various acts (Airenti, 2017).

Proficiency in pragmatic abilities varies widely across children of all ages (Matthews et al., 2017), with individual differences in this area showing positive associations with social 
competencies (e.g., peer relations; collaboration) and negative associations with challenges (e.g., behavioural difficulties, socio-emotional difficulties) (Hellend, Lundervold, Heimann, \& Posserud, 2014; Leonard, Milich, \& Lorch, 2011; Murphy, Faulkner, \& Farley, 2014). However, much less is understood about the specific factors that contribute to such variability in pragmatic abilities. This being said, recently, researchers have sought to uncover the factors associated with children's pragmatic abilities, including both temperamental and cognitive factors, discussed in turn below.

\section{Shyness and Pragmatic Abilities}

Shyness, reflecting a temperamental trait characterized by hesitation or discomfort in response to novel social stimuli, the avoidance of unfamiliar peers, less initiation of social interactions, and increased feelings of embarrassment/self-consciousness (Asendorpf, 1990; Asendorpf \& Meier, 1993), has been associated with a number of language and pragmatic challenges. For instance, children (in the age range of 4 to 6 years) who have elevated levels of shyness show weaker performance on expressive language tasks (Coplan \& Evans, 2009; Evans, 1996; Spere, Schmidt, Theall-Honey \& Martin-Chang, 2004; although see Coplan \& Armer, 2005). Moreover, Coplan and Weeks (2009) found that shy children were less competent in their use of contextual cues to generate appropriate responses to common social scenarios. As engagement with others is important for the development of a host of socio-communicative skills (e.g., de Rosnay \& Hughes, 2006; Dunn \& Brophy, 2005; Nelson, 2005), it may be the case that as shy children withdraw from social contexts, their opportunities to develop effective pragmatic skills become limited (Coplan \& Armer, 2005; Coplan \& Weeks, 2009). For instance, within 4year olds, a shy temperament is associated with more isolating behaviours and disconnection when playing with peers (Jahng, 2018), which may prevent them from learning how to 
coordinate their utterances with others, that is, with gaining skills in how to use language functionally (Nilsen \& Fecica, 2011). Further, it may be the case that greater social wariness relates to increased misinterpretation of communicative cues within social interactions, as evidenced by work showing that shy school-age children have more difficulty with interpreting nuanced communicative scenarios, such as faux pas (Banerjee \& Henderson, 2001), or speakers' intention behind more ambiguous language, such as ironic comments (Mewhort-Buist \& Nilsen, 2012).

The above findings speak to general associations, however, there is variability in shy children's pragmatic abilities, with not all shy children showing difficulty. Indeed, stronger pragmatic abilities seem to serve as a protective factor for shy children. For instance, shy children (in the older preschool age range) with poor vocabulary skills who possessed better pragmatic skills (as per parent report) were rated by their teachers as being more well-liked by peers (Cheung \& Elliott, 2017; also see Zhu, Li, Wood, Coplan, \& Chen, 2019). Further, shy 6year olds with weaker pragmatic abilities at the beginning of a school year, as measured by the Comprehensive Assessment of Spoken Language (CASL; Carrow-Woolfolk, 2008), tended to have worse socio-emotional outcomes later in the year (e.g., increased loneliness and social withdrawal; Coplan \& Weeks, 2009).

These latter findings speak to the importance of gaining further understanding of the variability in shy children's pragmatic abilities, as there are downstream (socio-emotional) consequences. In particular, it is beneficial to investigate factors that may moderate the relationship between shyness and pragmatic abilities. While past work has explored environmental factors that moderate associations between shyness and social adjustment (Coplan, Arbeau, \& Armer, 2008; Rubin, Wojslawowicz, Rose-Krasnor, Booth-LaForce, \& 
Burgess, 2006), little is known about the within-child factors, such as cognitive abilities, that may play a role in moderating aspects of shy children's functioning (Henderson, 2010). Further, moderators of the relationship between shyness and pragmatic ability have not been explored to date.

\section{Executive Functioning and Pragmatic Abilities}

One possibility is that there are differences in cognitive ability for shy children that affect the degree to which their temperament is associated with their pragmatic abilities. Indeed, a number of studies have sought to explore the cognitive skills that give rise to effective pragmatic abilities for children generally (Nilsen \& Fecica, 2011). In particular, children's executive functioning (EF), referring to higher order processes that serve to monitor and control thought and facilitate goal-directed behaviour (Burgess, 1997), have been examined. EF contains separable, but interrelated, components including working memory and inhibition - both widely viewed as central to the EF construct, predictive of other executive skills like cognitive flexibility, and differentially associated with more complex forms of behaviour, such as planning and problem-solving (Best \& Miller, 2010; Miyake et al., 2000). In theory, various pragmatic abilities would rely on EF: to form and interpret utterances, conversational partners must hold in mind contextual and linguistic information (drawing on working memory), to effectively take into account a conversational partner's perspective, the other partner needs to inhibit their own perspective (inhibitory control), and to adequately modify communicative utterances (or interpretations) as new information is introduced and/or when miscommunication is corrected, individuals require flexibility (cognitive flexibility). Associations have been examined empirically, typically falling into two categories: studies that manipulate EF demands within pragmatic tasks and studies examining associations between individual differences in EF and 
pragmatic abilities. With respect to the former, it has been found that increasing the working memory demands in pragmatic tasks leads to less skilled communication (e.g., less appreciation for one's conversational partner; Lin, Keysar, Epley, 2010; Roßnagel, 2000). A number of studies have explored relations between children's EF and performance on pragmatic tasks, demonstrating that preschool and school-age children with better working memory produce more successful messages (Bacso \& Nilsen, 2017; Wardlow \& Heyman, 2016; Nilsen, Varghese, Xu, \& Fecica, 2015) and children with better inhibitory control demonstrate a better ability to interpret statements based on the speaker's perspective (Nilsen \& Graham, 2009). Further, in a large study of over 400 6- to 9-year old children, EF (measured through the Wisconsin Cart Sorting Test) was related to the parent-reported reported socio-communicative skills (though there were differences in associations across gender; Dai, Lin, Liang, Wang, \& Jing, 2019). Interestingly, within 3- to 5-year olds, EF (assessed through a battery of tasks assessing working memory, inhibitory control, flexibility, and planning) seems to play a greater role in pragmatic abilities, such as fostering the production of fluid and clear utterances, than does IQ (BlainBrière, Bouchard \& Bigras, 2014). Together, given the associations between cognitive processes and pragmatic abilities throughout the preschool and school-age years, it may be the case that $\mathrm{EF}$ moderates the degree to which shy children face pragmatic challenges.

\section{Shyness, Executive Functioning, and Outcomes}

The notion that cognitive processing influences the effects of shyness on particular outcomes has been explored in a handful of studies focusing on domains outside of pragmatic abilities. For instance, different components of EF differentially impact the developmental risk for behaviourally inhibited children (biologically-based temperamental trait): those with greater attentional shifting tend to have more flexible and efficient goal-directed behaviour, whereas, 
those with increased response inhibition show exacerbated anxiety over time (Henderson, Pine, \& Fox, 2015; White, McDermott, Degnan, Henderson, \& Fox, 2011). Within a group of 9- to 13year-olds, higher shyness in combination with enhanced physiological responses during a flanker task predicted socio-emotional maladjustment (i.e., negative attribution styles, social anxiety, and poor perceptions of social acceptance; Henderson, 2011). Further, inhibitory control (as measured by parent report) moderated relations between shyness and school behaviours, such that shyness negatively related to prosocial behaviours for those preschool-age children with strong inhibitory control (Sette, Hipson, Zava, Baumgartner, Baiocco, \& Coplan, 2018).

However, representing a different pattern, EF (i.e., performance-based tasks of inhibitory control and working memory) has been found to be the mechanism by which shy preschool-age children have weaker verbal skills, in that shy children's negative arousal within social contexts may prevent them from applying the cognitive control needed to support vocabulary development (Blankson, O’Brien, Leerkes, Marcovitch, \& Calkins, 2011).

Together this body of work suggests that shyness may not universally be associated with specific outcomes, but that the cognitive skills of shy children plays an important role (Henderson \& Wilson, 2017). Though there are methodological differences across studies (tasks, age of participants) which makes a direct comparison difficult, together the work also highlights an important theoretical complication, namely, that some aspects of EF (e.g., inhibitory control) may be protective for certain aspects of shy children's functioning, while exacerbating risk in other domains. Thus, further research investigating the moderating role of cognitive skills for shy children's functioning is needed.

\section{Present Investigation}


Our overall aim was to investigate whether EF moderates the association between shyness and pragmatic abilities. However, one issue the field of pragmatic abilities has faced is a difference in how it is assessed across studies (e.g., use of structured tests, conversational analysis, or observer-report measures; Adams, 2002; Russell \& Grizzle, 2008). The use of measures is an important consideration when clarifying the difference between what a child knows they should be saying in a particular situation versus what they actually say when navigating complex social interactions. Thus, when considering the global ability of pragmatics, we sought to differentiate between pragmatic knowledge versus the demonstration of pragmatic abilities. Outside of shyness, this distinction has been observed: for instance, children with ADHD were able to reflect on the appropriate use of language for a given context, but during a conversation did not demonstrate similarly skilled behaviour (Kim \& Kaiser, 2000). Within the shyness literature, there has been speculation that shy children's difficulties are more reflective of performance rather than understanding, stemming from observations that their scores on expressive language tests tend to be lower than on receptive tests (Coplan \& Evans, 2009; Spere et al., 2004). Though, studies examining shy children's pragmatic abilities to date have focused on either knowledge or demonstrated abilities, which limits the ability to make strong claims. In the present work, we explored associations between shyness and both these aspects.

More specifically, we assessed whether children's EF affects the degree to which shyness is associated with both pragmatic knowledge (i.e., children's awareness of what should be said in social situations; measured by a task that assessed children's ability to generate appropriate responses to social vignettes) and demonstrated abilities (i.e., how well children do at using language functioning to interact with others in their everyday settings; measured by parentreport). We had anticipated that shyness would be associated with both pragmatic knowledge and 
demonstrated ability, with the former prediction based on past work (e.g., Coplan \& Weeks, 2009) and the latter drawing from the notion that a shy temperament may hinder the demonstration of communicative skills in social contexts (Jahng, 2018).

However, we further anticipated that the relationship between shyness and pragmatic ability would be moderated by children's EF. With respect to our measurement of EF, we focused on children's working memory and inhibitory control given the associations these components have with pragmatic abilities (irrespective of shyness; see Matthews et al., 2018 and Nilsen \& Fecica, 2011 for reviews), as well as the degree to which they are thought of as the foundational components of EF (Best \& Miller, 2010). Past work has shown that the way components of $\mathrm{EF}$ are measured may capture different underlying constructs (Toplak, West, \& Stanovich, 2013). Thus, we utilized both performance-based measures of EF and demonstrated challenges in the application of EF in everyday settings through parent-report.

Based on work demonstrating the role of task-based $\mathrm{EF}$ in various aspects of pragmatic ability (e.g., Matthews et al., 2018) we expected strong EF would be associated with better pragmatic knowledge and demonstrated abilities. Though, we had anticipated that it may be the case that performance-based measures of EF would moderate associations between shyness and pragmatic knowledge, whereas parent-reported EF may play a role in moderating associations between shyness and demonstrated pragmatic ability, in both cases, with stronger EF weakening the relationship between shyness and pragmatic challenges. This being said, as noted above, EF has been found to play divergent roles (as measured by both tasks and parent-report) for shy children's functioning in other social domains (Sette et al., 2018; White et al., 2011). Thus, we recognized that, contrary to predictions, it may be the case we would find that strong EF exacerbates pragmatic difficulties for children with elevated shyness. 
Predictions notwithstanding, our use of multi-measures and multi-informants allowed us to limit concerns regarding shared method variance. That is, we were able to explore whether associations between shyness and pragmatic knowledge/demonstration were moderated by EF using measures from different respondents (child/parent) and/or methodology (performance versus parent-report).

\section{Method}

\section{Participants}

Participants were 84 children between the ages of 8 and 11 years-old ( 47 females; 8.25 11 years) from the community in a mid-sized Canadian city. Participant data was excluded when participants had suspected or diagnosed Autism Spectrum Disorder (ASD) $(n=3)$. The resulting sample consisted of 81 children (47 females; $8.29-11.07$ years; $M=9.49$ years, $S D=0.89$ years). Of the parents who provided information on the open-ended question regarding their child's ethnic background $(n=81), 77 \%$ indicated their child was Caucasian, and $23 \%$ indicated they were from a South Asian, Middle Eastern, First Nations, Latin background or mixed. Ninety-seven percent of parents indicated that English was the predominant language spoken at home. Seventy percent of mothers and $67 \%$ of fathers reported a university degree or higher.

\section{Materials and Procedure}

Following parental consent and child assent, participants completed tasks in a laboratory setting in a standardized order (i.e., pragmatic knowledge, working memory, inhibitory control, and expressive vocabulary $)^{1}$ during an hour session. Meanwhile, parents completed questionnaires in an adjacent waiting room. Children received a small monetary gift (i.e. a toy or

\footnotetext{
${ }^{1}$ Only a subset of participants $(N=44)$ were administered the expressive vocabulary measure.
} 
a gift card) for their participation. This study was approved by the Research Ethics Committee at the University of Waterloo.

\section{Pragmatic Abilities}

\section{Pragmatic knowledge.}

The Pragmatic Judgment subtest of the Comprehensive Assessment of Spoken Language (CASL; Carrow-Woolfolk, 2008) measured children's pragmatic knowledge, in particular children's awareness of appropriate language in relation to specific social situations (CarrowWoolfolk, 2008). The CASL has high construct and criterion-related validity and strong reliability (Carrow-Woolfolk, 2008; Turkstra, Williams, Tonks, \& Frampton, 2008). The pragmatic judgment subtest has previously demonstrated high internal consistency (90\%) and test-retest reliability (.84; Carrow-Woolfolk, 1999; Coplan \& Weeks, 2009). In this task, the experimenter read a series of 60 increasingly difficult items, describing social scenarios such as such as answering the telephone, or making a request. Participants attempted to generate appropriate communicative responses for each scenario. Early items are scored based on 0 (incorrect) or 1 (correct), whereas later items are scored from 0 (incorrect) to either 2 or 3 (complete answer) with 1 to 2 points awarded if partial answers were provided, based on the standardized scoring provided by the manual. Thus, total possible scores ranged from 0-68, with higher scores reflecting greater pragmatic knowledge. Once 5 incorrect responses had been given, the task was discontinued. Participant's raw scores were used in the analysis.

\section{Demonstrated pragmatic ability.}

Parents completed the Children's Communication Checklist - 2nd U.S. Edition (CCC-2; Bishop, 2003) to assess children's demonstrated pragmatic abilities in everyday settings. The CCC-2 is a well-validated tool for examining pragmatic language in both typical and atypical 
populations of children between the ages of 4 to 16 years old (Bishop, 2006; Ferrara et al., 2020; Parsons, Cordier, Munro \& Joosten, 2019; Volden \& Phillips, 2010). It demonstrates strong psychometric properties (e.g., internal consistency values ranging from .94-.96; Bishop, 2003; and .73-.89; Helland, Biringer, Helland, \& Heimann, 2009; Helland, 2014) and strong interrater agreement (.93; Bishop, 2003). Parents were asked to reflect on their children's communicative acts using a 4-point Likert scale from 0 (less than once a week (or never) to 3 (several times (more than twice) a day (or always). For the first 50 questions, a higher rating indicated more communicative difficulties in everyday settings, whereas for the final 20 questions a higher rating indicated communicative strength when interacting with others (with these latter items reverse scored). The 10 subscales ( 7 items per subscale) included in the CCC-2 cover a variety of topics relating to language structure and pragmatic skills (Bishop, 2003). In earlier versions of the CCC (Bishop, 1998), a standardized pragmatic composite was included. While this is not included in the English CCC-2, the subscales that were used are still available. Thus, for the purposes of this study, a pragmatic composite, was included as the measure of children's demonstration of pragmatic abilities in their everyday lives. We combined the following subscales to create a pragmatic composite: initiation, coherence, scripted language, use of context, and nonverbal communication, which would allow for an understanding as to parents' observations of their children's ability to initiate and sustain conversations with others by accurately using cues from conversational partners and the situation and regulating their own behaviour accordingly (See Nilsen et al., 2013; Bishop, 1998; Botting, 2004; Ketelaars, Cuperus, van Daal, Jansonius \& Verhoeven, 2009; Bishop \& Baird, 2001; Geurts et al., 2004; Anderson Helland \& Heimann, 2007, for similar procedures). Within this sample, the pragmatic composite 
exhibited good reliability ( $\alpha=.80$ ), with higher scores reflecting more difficulty or challenge in demonstrated pragmatic abilities.

\section{Executive Functioning}

\section{Performance-based tasks}

Children were administered two EF tasks to assess working memory (WM) and inhibitory control (IC).

Working memory. The Backward Digit Span subtest from the Wechsler Intelligence Scale for Children - Fourth Edition (WISC-IV; Wechsler, 2003) assessed children's WM. Previous factor analyses of EF measures have shown span tasks to load on factors of WM (Gathercole, Pickering, Ambridge, \& Wearing, 2004; McAuley \& White, 2011). In this task, the researcher read strings of digits of increasing length for participants to repeat in reverse order ${ }^{2}$. The task consisted of 8 items (which ranged from 2 to 9 digits), with 2 trials per string length, scored as 1 (correct) or 0 (incorrect), for a total trial score of 0-2 per string length. The researcher discontinued their administration if a child provided an incorrect response for both trials of one string length. Possible raw scores ranged from 0-16.

Inhibitory control. To assess children's IC skills, researchers administered the colourword interference subtest from the Delis-Kaplan Executive Function System (DKEFS; Delis, Kaplan, \& Kramer, 2001), which is a variation of the Stroop test (Stroop, 1935) seen as a benchmark of inhibitory control (Wright, Waterman, Prescott, \& Murdoch-Eaton, 2003). Participants were first presented with colour swatches and asked to name the colours (colour naming condition), then were asked to read a list of colour words in order to control for things such as reading speed (word reading condition). Next, participants were presented with colour

\footnotetext{
${ }^{2}$ The researcher administered digit span forward (where children repeated digits back in the same order as provided by the researcher) prior to administering digit span backward.
} 
words that differed from the colour of ink they were written in (i.e., "red" in blue ink) and were asked to say the ink colour, thus inhibiting the initial response to simply read the word (inhibition condition). Interference control, our measure of inhibition skills, was calculated by regressing the time children took to complete the inhibition condition on the time children took to complete the word reading condition and saving the standardized residuals wherein a higher score reflected slower performance (i.e., weaker interference control).

Children's performance on the backward digit span and colour-word interference test were not significantly correlated $(p=.59)$. Thus, these constructs were considered separately in the analyses.

\section{Parent-report of EF}

Parents were asked to complete The Childhood Executive Functioning Inventory (CHEXI), which assesses challenges in children's (ages 4 - 12 years) real-world application of executive skills in the areas of working memory (WM), planning, inhibition (IC), and regulation (Thorell \& Nyberg, 2008). Parents were asked to rate 24 items such as "has difficulty remembering lengthy instructions" and "when something needs to be done, he/she is often distracted by something more appealing", on a 5-point scale from 1 (Definitely not true) to 5 (Definitely true). This instrument is reported to have good test-retest reliability $(r=.89)$ along with well-established validity (Thorell \& Nyberg, 2008). To have a measure that reflected similar constructs to the tasks administered, the WM (9 items) and IC (6 items) subscales (which were correlated, $p<.001)$ were combined to create a total parent-reported EF score, which revealed a good reliability within this sample $(\alpha=.92)$. For scoring, a higher score is indicative of worse EF skills, that is, of executive dysfunction.

\section{Shyness}


To assess participants' level of shyness, children completed the Child Shyness Questionnaire (CSQ; Crozier, 1995); a self-report measure designed to assess fearful and selfconscious aspects of shyness. This task was originally developed using words generated by children to describe the phrase "being shy", and, as such, demonstrates good face validity for this age group. Children rated 26 statements and/or questions such as "I go red when someone teases me" and "I enjoy having my photograph taken" (reverse-scored), on as 3-point Likert scale: 2 (yes), 1 (maybe), 0 (no). To aid in the ease of administration of this measure, the seven items that were worded as questions in the CSQ were reworded for this study to make all items first person statements, consistent with the majority of the original items (e.g., the item, "Do you blush a lot?" was reworded to "I blush a lot"). In addition, some wording was changed to make the items applicable to North American children (i.e., "Head Teacher" was changed to "Principal"). Children's responses were summed to create a final score where higher scores reflect elevated self-reported shyness. The original form of this measure has been shown to have good internal consistency ( $\alpha=.82$; Crozier, 1995), with the responses to items from the present sample also showing good reliability $(\alpha=.85)$.

\section{Expressive Vocabulary}

To ensure that findings could not be attributed to basic language skills, a subset of 44 participants completed the expressive vocabulary task of the Wechsler Individual Achievement Test-II (WIAT-II; Wechsler, 2001). In this task, the researcher presented pictures and the child had to indicate the appropriate name for the picture, scored as 0 (incorrect) or 1(correct).

\section{Results}

\section{Preliminary Analyses}


Decisions regarding sample size were informed by an a priori power analysis conducted using GPower (Faul, Erdfelder, Buchner, \& Lang, 2009). This analysis indicated that a sample of approximately 80 children would be appropriate for conducting multiple regression in which we are specifically interested in testing the incremental variance explained by the interaction terms given alpha of .05 , power of .80 , and a medium effect size. The data that support the findings of this study are available from the corresponding author upon reasonable request.

Univariate outliers in the data were Winsorized to be within $3 S D$ of the mean - a wellestablished threshold in behavioural sciences research (e.g., Osborne \& Overbay, 2004) (CCC-2 pragmatic composite, $n=2$; CHEXI composite, $n=1$; DKEFS residual time, $n=1, \mathrm{CSQ}, n=1$ ). Missing data, reflecting less than $.01 \%$ of data (CCC-2 pragmatic composite, 1 item; CHEXI, 1 item; CSQ, 7 items missing across 6 participants) was imputed using single imputation (Eekhout et al., 2014). Predictors were approximately normally distributed based on inspection of histograms coupled with values of skew and kurtosis. There were no multivariate outliers based on inspection of Mahalanobis distance. No participants were excluded from analyses of the CASL. Three participants were excluded from analyses involving the CCC-2: one who was missing the full CCC-2 questionnaire, and two others who emerged as extreme outliers in the regression analyses based on inspection of standardized residuals. Residual plots were inspected to check and confirm the assumptions of OLS regression (e.g., Osborne \& Waters, 2002). Descriptive statistics for the measures are provided on Table 1. Bivariate and partial correlations (controlling for age and gender) between measures of interest are provided on Table 2. Some notable associations emerged: shyness was significantly related to children's pragmatic knowledge, but not parent-reported pragmatic abilities (though the two pragmatic measures had a trend-level association with each other; $p=.06$ ). Performance-based measures of EF (WM and 
IC) showed significant positive correlations with children's pragmatic knowledge (though, the association with WM became non-significant when controlling for age). Parent-reported EF related to both children's pragmatic knowledge and parent-ratings of their demonstrated pragmatic abilities (wherein stronger EF related to better pragmatic abilities). As both age and gender showed significant correlations with children's pragmatic knowledge and demonstrated abilities, these factors were included in both regression analyses.

\section{Regression Analyses}

Hierarchical regression models examined the contribution of predictors to children's pragmatic knowledge (CASL pragmatic judgment subtest) and parent ratings of their pragmatic abilities (CCC-2 pragmatic composite). After controlling for age and gender in the first step, main effects reflecting children's shyness, performance on EF tasks, and parent ratings of children's EF were entered into a second step, followed by interactions between shyness and each of the EF indicators into the third step. Predictors involved in the creation of interaction terms were mean-centered. Non-significant interactions were eliminated from the final models. Significant interactions were subsequently examined using simple slopes analysis in PROCESS with all other variables entered as covariates (Hayes, 2017).

Results of the regression analysis for the CASL pragmatic judgment subtest are presented in Table 3. The interactions between shyness (CSQ) and the performance-based measures were non-significant, so were removed from the models (i.e., CSQ x WM: $B=.07, S E=.06, p=.20$; CSQ x IC: $B=-.003, S E=.005, p=.59)$. Thirty-seven percent of variance in children's CASL pragmatic judgment scores was predicted in the final model overall. CASL scores significantly increased with increasing age, having stronger response inhibition, and trended to being better among girls. There also was a significant interaction between children's shyness and parent 
ratings of their EF, which uniquely explained 3\% of variance in children's CASL scores. The regression of CASL scores on children's shyness was further explored at low (-1 SD), average, and high (+1 SD) levels of EF challenge. As shown in Figure 1, children with few EF challenges had high pragmatic knowledge (as measured by the CASL) irrespective of shyness $(B=.004, S E$ $=.12, t=.03, p=.97)$ whereas increasing shyness significantly predicted lower pragmatic knowledge amongst children in whom EF challenges were average $(B=-.18, S E=.08, t=-2.20$, $p=.03)$ or high $(B=-.36, S E=.13, t=-2.83, p=.006)$.

Results of the regression analysis for the CCC-2 pragmatic composite are presented in Table 4. The interactions between shyness (CSQ) and the performance-based measures were non-significant, so were removed from the models (i.e., CSQ x WM: $B=.03, S E=.04, p=.50$; CSQ x IC: $B=.002, S E=.004, p=.62)$. Fifty percent of variance in parent ratings of children's demonstrated pragmatic abilities was predicted in the final model overall. Concerns regarding pragmatic challenges were significantly lower amongst parents of female children and lessened with increasing age. There also was a significant interaction of children's shyness and parent reports of EF, which uniquely explained $6 \%$ of variance in $\mathrm{CCC}-2$ ratings. As shown in Figure 2, parents had relatively few concerns regarding their children's pragmatic abilities when EF challenges were average $(B=.06, S E=.07, t=.96, p=.34)$ or low $(B=-.15, S E=.10, t=-1.53$, $p=.13$ ) - irrespective of shyness. Conversely, increasing shyness significantly predicted greater parental endorsement of pragmatic challenges amongst children in whom EF challenges were $\operatorname{high}(B=.27, S E=.10, t=2.74, p=.008)$.

\section{Controlling for vocabulary}

When scores from the subset of participants who completed the WIAT-II; Wechsler, 2001) were entered into the regression analyses within the first step, the interaction of shyness 
and EF remained significant in each model (CASL: $B=-.04, S E=.02, t=-2.37, p=.02$; CCC-2: $B=.03, S E=.01, t=2.36, p=.03)$. Thus, the findings above remain when vocabulary scores are controlled.

\section{Discussion}

The present work sought to explore whether individual differences in EF may provide insight into why shyness is associated with weaker pragmatic abilities for some, but not all shy children.

If we only looked at main effects, our findings would replicate previous work in this area. For instance, consistent with past work (Coplan \& Weeks, 2009), children with higher levels of shyness were less successful at generating socially-appropriate responses within various scenarios. Though, contrary to our prediction (and running contrary to the notion that shy children's main area of difficulty is in enacting rather than knowing what to say), we did not find that children's shyness related to their parent's report of their demonstrated pragmatic abilities. However, it may have been the case that within the contexts that parents are observing their children (namely within a home environment) there is less observed challenge relative to what would be observed in social contexts with less familiar individuals (Asedorpf \& Meier, 1993). For instance, teachers' reports on the social functioning of shy children within a classroom context reflect less success relative to the report of non-shy students (Cheung \& Elliot, 2017; Coplan \& Armer, 2005; Coplan \& Weeks, 2010). Second, replicating previous work showing associations between EF and other aspects of pragmatics (e.g., Blain-Brière et al., 2014; Rints, McAuley, \& Nilsen, 2015), children with better performance on inhibitory control showed better pragmatic knowledge. Further, parents who reported fewer EF concerns for their child viewed them as demonstrating more proficient pragmatic abilities in their everyday environments. 
However, our primary focus was exploring the interaction between shyness and EF. Providing a novel contribution to the literature, the present findings demonstrated that the associations between shyness and both pragmatic knowledge and demonstrated pragmatic abilities were moderated by parent-reported, but not performance-based, EF. More specifically, children who self-reported higher levels of shyness only demonstrated lower pragmatic knowledge when their parent-reported EF challenges were average or high. When parents reported fewer difficulties with $\mathrm{EF}$, the pragmatic judgment scores (on the CASL) of shy children were comparable to their non-shy peers. Further, children with high levels of shyness were viewed by their parents as demonstrating weaker pragmatic abilities only when the parents also reported high levels of EF difficulty. Thus, we found a similar pattern of results using measures that relied on different informants (e.g., child and parent) and across methodologies (e.g., task-based pragmatic knowledge and parent-report of demonstrated abilities). These patterns of results cannot be attributed to differences in more basic language skills, as patterns remained when controlling for expressive vocabulary in a subset of children. Together results suggest that having and applying strong EF (as observed by parents) seems to buffer shy children against pragmatic difficulties. However, the caveat to this conclusion is that performance-based EF did not emerge as a significant moderator, as discussed further below.

Interpreting the parent-reported EF moderation further, it seems that possessing strong EF abilities may support pragmatic skill development such that temperamental features do not play a role. One theoretical model of communication (Nilsen \& Fecica, 2011) posits that there are various avenues by which children could develop successful pragmatic abilities (or, conversely, face challenges). Of relevance to this work, one route outlines the need for children to have adequate cognitive processes to support appropriate communicative acts. That is, beyond 
recognizing the needs of conversational partners, they must have the skills to make use of this information in a meaningful way. Another important aspect of pragmatic development is through sufficient quality (and quantity) of experience with social interactions. Thus, in the case of shy children, withdrawal from social experiences would limit opportunities for language and pragmatic development (Blankson et al., 2011). The present work finds support for each individual route (i.e., better inhibition related to better pragmatic knowledge; high shyness was associated with decreased pragmatic knowledge), but suggests that these routes may interact. That is, while it may be the case that shy children generally have fewer direct social experiences, this may not be detrimental to the development of pragmatic abilities if a shy child has the ability to apply their executive skills in everyday settings. In essence, these shy children may require less direct experience with social interactions in order to learn from them. Various past studies have demonstrated that the act of observing social contexts from a distance may provide shy children with the exposure they need to develop better socio-cognitive skills (LaBounty, Bosse, Savicki, King, \& Eisenstat, 2017; Mink, Henning, \& Aschersleben, 2014). The present work suggests that such benefit (albeit in the pragmatic domain opposed to mental state reasoning), may be accrued if sufficient cognitive processes (as reflected by children's observable behaviours) are present.

Performance-based EF measures, specifically, response inhibition, was associated with pragmatic knowledge, suggesting that children with better inhibition skills may be better able to reflect on, and select, appropriate communicative responses in a more deliberate, and less impulsive fashion. However, contrary to our predictions, and contrasting past work showing divergent roles of inhibition for shy children's functioning (White et al., 2011), neither performance-based measure (i.e., of inhibition or working memory) moderated relations between 
shyness and pragmatic abilities. This finding suggests that these factors independently account for variance in pragmatic abilities (specifically, in this study, for pragmatic knowledge) rather than interacting.

In the present work, parent report of EF and performance-based measures were not found to be significantly related, which is consistent with much work (e.g., Liebermann, Giesbrecht, \& Müller, 2007; Mahone \& Hoffman, 2007; Toplak et al., 2013). Toplak and colleagues (2013) argue that rating scales of EF tend to capture different underlying constructs than performance measures: rating scales capture success in goal pursuit while performance measures capture efficiency of information processing. Further, lab-based measures are often administered in an environment that is free from distraction, with well-defined goals, and thus may not capture the ability to apply executive function skills in more complex contexts (Nilsen, Huyder, McAuley, \& Liebermann, 2017) ${ }^{3}$. This distinction may be important to understanding the pattern in our data. Namely, while speculative, it may be that for shy children to have sufficient pragmatic abilities they require the ability to deploy EF within everyday contexts (as opposed to EF, as assessed in isolation within controlled contexts). In essence, being able to effectively use their executive function skills may allow them to more effectively engage with their environments and thus, gain experiences that support pragmatic abilities. On the other hand, it is important to consider that the parent-report measure asked about executive $d y s$ function (as is the case with the majority of EF questionnaires; Nilsen, Huyder, McAuley, \& Liebermann, 2016). Thus, it may be the case that EF capacity is not what is important, it is the absence of dysfunction, as demonstrated in everyday behaviour, that is key. Although it is important to acknowledge that we cannot

\footnotetext{
${ }^{3}$ For instance, in the present study, the task of WM was to hold digits in mind whereas parents reported on their children's difficulty with activities such as remembering instructions or forgetting what he/she was asked to fetch; the task of IC required children to suppress a dominant response (saying the word), whereas parents reported on their children's difficulty with holding back or stopping activities, even when requested to do so.
} 
confidently interpret the null findings given that we underpowered to detect effects that were small.

While this study yields important findings, there are also limitations to mention. First, we recognize that a significant yet modest amount of variance in children's pragmatic abilities was explained by the interaction of shyness with executive dysfunction (per parent report). This may reflect our selection of EF measures, which were designed to assess core components of the construct - namely, working memory and inhibitory control. It is likely, however, that other executive skills also contribute to children's pragmatic development. In particular, we suggest that cognitive flexibility is a compelling candidate for inclusion in future work because it has previously been identified as an important factor in children's ability to communicate - such as using feedback from conversational partners to repair miscommunication (Bacso \& Nilsen, 2017) and understanding irony (Zajączkowska \& Abbot-Smith, accepted). Relatedly, given that a large proportion of variance in children's pragmatic abilities was attributable to demographic factors, in future work it may prove insightful to explore the interplay of shyness and EF in different age and/or gender groups. Regarding the latter, for example, other studies have shown that shyness has a more negative impact on social-emotional functioning in boys versus girls (Coplan, Closson, \& Arbeau, 2007) and that certain language skills (e.g., irony comprehension) differentially affect these relations across genders (Mewhort-Buist \& Nilsen, 2019). Lastly, our findings must be interpreted within the context of a cross-sectional research design, which precludes us from exploring directionality or commenting upon possible causal relationships. Future work could employ longitudinal methodology to clarify how temperamental factors and cognitive processes uniquely and jointly support pragmatic development and to identify potential consequences for social-emotional functioning - associations shown to be complex and 
sometimes contradictory based on extant work (e.g., Coplan \& Weeks, 2009; Mewhort-Buist \& Nilsen, 2019; White et al., 2011).

In sum, the present work finds that, while shyness was associated with weaker pragmatic knowledge, individual differences in children's application of EF (as reported by parents) play an important role in moderating associations between shyness and pragmatic abilities. Those children who are high in shyness, but show strong EF (or, rather, the absence of executive dysfunction), have pragmatic knowledge and demonstrated abilities that are generally on par with their non-shy peers. The findings have methodological and practical implications: first, given the discrepancy in results for performance versus parent-report measures, researchers need to pay careful attention to how EF and pragmatic abilities are measured when consolidating findings across studies and developing research projects. Second, professionals may be better able to identify children at risk for pragmatic difficulties by attending to both temperamental and cognitive factors. Further, as interventions aimed at enhancing pragmatic ability are developed/implemented, professionals could look at whether individual differences affect children's response to treatment. 


\section{References}

Adams, C. (2002). Practitioner review: The assessment of language pragmatics. Journal of Child Psychology and Psychiatry, 43, 973-987. doi: 10.1111/1469-7610.00226

Airenti, G. (2017). Pragmatic development. In L. Cummings (Ed.). Research in clinical pragmatics. Perspectives in Pragmatics, Philosophy \& Psychology, Vol 11 (pp. 3-28). Springer. doi: 10.1007/978-3-319-47489-2_1

Akbar, M., Loomis, R., \& Paul, R. (2013). The interplay of language on executive functions in children with ASD. Research in Autism Spectrum Disorders, 7, 494-501. doi: 10.1016/j.rasd.2012.09.001

Andersen Helland, W., \& Heimann, M. (2007). Assessment of pragmatic language impairment in children referred to psychiatric services: A pilot study of the Children's Communication Checklist in a Norwegian sample. Logopedics Phoniatrics Vocology, 32, 23-30. doi: $10.1080 / 14015430600712056$

Ariel, M. (2010). Defining pragmatics. New York: Cambridge University Press.

Asendorpf, J. B. (1990). Beyond social withdrawal: Shyness, unsociability, and peer avoidance. Human Development, 33, 250-259. doi: 10.1159/000276522

Asendorpf, J. B., \& Meier, G. H. (1993). Personality effects on children's speech in everyday life: Sociability-mediated exposure and shyness-mediated reactivity to social situations. Journal of Personality and Social Psychology, 64, 1072. doi: 10.1037/0022-3514.64.6.1072

Bacso, S. A., \& Nilsen, E. S. (2017). What's that you're saying? Children with better executive functioning produce and repair communication more effectively. Journal of Cognition and Development, 18, 441-464. doi: 10.1080/15248372.2017.1336438

Banerjee, R., \& Henderson, L. (2001). Social-cognitive factors in childhood social anxiety: A preliminary investigation. Social Development, 10(4), 558-572. doi: 10.1111/1467-9507.00180 
Bates, E., Camaioni, L., \& Volterra, V. (1975). The acquisition of performatives prior to speech. Merrill-Palmer Quarterly of Behavior and Development, 21, 205-226.

Best, J. R., \& Miller, P. H. (2010). A developmental perspective on executive function. Child development, 81(6), 1641-1660.

Bishop, D. V. (1998). Development of the Children's Communication Checklist (CCC): A method for assessing qualitative aspects of communicative impairment in children. The Journal of Child Psychology and Psychiatry and Allied Disciplines, 39, 879-891. doi:

$10.1017 / \mathrm{S} 0021963098002832$

Bishop, D. V. M. (2003). Children's Communicative Checklist-2. San Antonio, TX: The Psychological Corporation.

Bishop, D. (2006). Children's Communication Checklist (2nd ed.). San Antonio, TX: Pearson.

Bishop, D. V., \& Baird, G. (2001). Parent and teacher report of pragmatic aspects of communication: use of the Children's Communication Checklist in a clinical setting. Developmental Medicine and Child Neurology, 43, 809-818. doi: 10.1017/S0012162201001475

Blain-Brière, B., Bouchard, C., \& Bigras, N. (2014). The role of executive functions in the pragmatic skills of children age 4-5. Frontiers in Psychology, 5, 240. doi: 10.3389/fpsyg.2014.00240

Blankson, A. N., O’Brien, M., Leerkes, E. M., Marcovitch, S., \& Calkins, S. D. (2011). Shyness and vocabulary: The roles of executive functioning and home environmental stimulation. MerrillPalmer Quarterly (Wayne State University. Press), 57, 105.

Botting, N. (2004). Children's Communication Checklist (CCC) scores in 11-year-old children with communication impairments. International Journal of Language \& Communication Disorders, 39, 215-227. doi: 10.1080/13682820310001617001 
Blain-Brière, B., Bouchard, C., \& Bigras, N. (2014). The role of executive functions in the pragmatic skills of children age 4-5. Frontiers in Psychology, 5, 240. doi: 10.3389/fpsyg.2014.00240

Burgess, P. (1997). Theory and methodology in executive function research. In P. Rabbitt (Ed.), Methodology of Frontal Executive Function (pp. 81-116). East Sussex, UK: Psychology Press.

Carrow-Woolfolk, E. (2008). CASL: Comprehensive Assessment of Spoken Language (Manual). Los Angeles, CA: Western Psychological Services.

Cheung, H. S., \& Elliott, J. M. (2017). Child shyness and peer likeability: The moderating role of pragmatics and vocabulary. British Journal of Developmental Psychology, 35, 531-545. doi: 10.1111/bjdp.12192

Clark, E. V. (2003). First language acquisition. Cambridge, United Kingdom: Cambridge University Press.

Coplan, R. J., Arbeau, K. A., \& Armer, M. (2008). Don't fret, be supportive! Maternal characteristics linking child shyness to psychosocial and school adjustment in kindergarten. Journal of Abnormal Child Psychology, 36, 359-371. doi: 10.1007/s10802-007-9183-7

Coplan, R. J., \& Armer, M. (2005). Talking yourself out of being shy: Shyness, expressive vocabulary, and socioemotional adjustment in preschool. Merrill-Palmer Quarterly (1982-), 20-41.

Coplan, R. J., Closson, L. M, \& Arbeau, K. A. (2007). Gender differences in the behavioral associates of loneliness and social dissatisfaction in kindergarten. Journal of Child Psychology and Psychiatry, 48, 988-995. doi: 10.1111/j.1469-7610.2007.01804.x

Coplan, R. J., \& Evans, M. A. (2009). At a loss for words? Introduction to the special issue on shyness and language in childhood. Infant and Child Development, 18, 211-215. doi: 10.1002/icd.620 
Coplan, R. J., \& Weeks, M. (2009). Shy and soft-spoken: shyness, pragmatic language, and socioemotional adjustment in early childhood. Infant and Child Development, 18, 238-254. doi: $10.1002 /$ icd. 622

Crozier, W. R. (1995). Shyness and self-esteem in middle childhood. British Journal of Educational Psychology, 65, 85-95. doi: 10.1111/j.2044-8279.1995.tb01133.x

Dai, M., Lin, L., Liang, J., Wang, Z., \& Jing, J. (2019). Gender difference in the association between executive function and autistic traits in typically developing children. Journal of Autism and Developmental Disorders, 49, 1182-1192. doi: 10.1007/s10803-018-3813-5

Dale, P. S. (1980). Is early pragmatic development measurable? Journal of Child Language, 7, 1-12. doi: $10.1017 / \mathrm{S} 0305000900006991$

Delis, D. C., Kaplan, E., \& Kramer, J. H. (2001). Delis-Kaplan executive function system. Examiner's Manual. San Antonio: The Psychological Corporation.

de Rosnay, M., \& Hughes, C. (2006). Conversation and theory of mind: Do children talk their way to socio-cognitive understanding?. British Journal of Developmental Psychology, 24(1), 7-37. doi: $10.1348 / 026151005 \times 82901$

Dunn, J., \& Brophy, M. (2005). Communication, relationships, and individual differences in children's understanding of mind. In J. W. Astington \& J. A. Baird (Eds.), Why language matters for theory of mind (pp. 50-69). Oxford University Press. doi: 10.1093/acprof:oso/9780195159912.003.0003

Eekhout, I., de Vet, H. C., Twisk, J. W., Brand, J. P., de Boer, M. R., \& Heymans, M. W. (2014). Missing data in a multi-item instrument were best handled by multiple imputation at the item score level. Journal of Clinical Epidemiology, 67(3), 335-342. 
Evans, M. A. (1996). Reticent primary grade children and their more talkative peers: Verbal, nonverbal, and self-concept characteristics. Journal of Educational Psychology, 88, 739. doi: 10.1037/00220663.88.4.739

Faul, F., Erdfelder, E., Buchner, A., \& Lang, A. G. (2009). Statistical power analyses using G* Power 3.1: Tests for correlation and regression analyses. Behavior Research Methods, 41, 1149-1160. doi: $10.3758 / B R M .41 .4 .1149$

Ferrara, M., Camia, M., Cecere, V., Villata, V., Vivenzio, N., Scorza, M., \& Padovani, R. (2020). Language and pragmatics across neurodevelopmental disorders: An investigation using the Italian version of CCC-2. Journal of Autism and Developmental Disorders, 1-15. doi: 10.1007/s10803-019-04358-6

Filippova, E., \& Astington, J. W. (2008). Further development in social reasoning revealed in discourse irony understanding. Child Development, 79, 126-138. doi: 10.1111/j.1467-8624.2007.01115.x

Gathercole, S. E., Pickering, S. J., Ambridge, B., \& Wearing, H. (2004). The structure of working memory from 4 to 15 years of age. Developmental Psychology, 40, 177. doi: 10.1037/00121649.40 .2 .177

Geurts, H. M., Verté, S., Oosterlaan, J., Roeyers, H., Hartman, C. A., Mulder, E. J., ... \& Sergeant, J. A. (2004). Can the Children's Communication Checklist differentiate between children with autism, children with ADHD, and normal controls? Journal of Child Psychology and Psychiatry, 45, 1437-1453. doi: 10.1111/j.1469-7610.2004.00326.x

Harris, M., \& Pexman, P. M. (2003). Children's perceptions of the social functions of verbal irony. Discourse Processes, 36, 147-165. doi: 10.1207/S15326950DP3603_1

Hayes, A. F. (2017). Introduction to mediation, moderation, and conditional process analysis: A regression-based approach. Guilford Publications. 
Helland, W. A. (2014). Differentiating children with specific language impairment and children with Asperger syndrome using parental reports. Annals of Psychiatry and Mental Health, 2(3), 1013.

Helland, W. A., Biringer, E., Helland, T., \& Heimann, M. (2009). The usability of a Norwegian adaptation of the Children's Communication Checklist Second Edition (CCC-2) in differentiating between language impaired and non-language impaired 6-to 12-year-olds. Scandinavian Journal of Psychology, 50, 287-292. doi: 10.1111/ j.1467-9450.2009.00718.x

Helland, W. A., Lundervold, A. J., Heimann, M., \& Posserud, M. B. (2014). Stable associations between behavioral problems and language impairments across childhood-The importance of pragmatic language problems. Research in Developmental Disabilities, 35, 943-951. doi: 10.1016/j.ridd.2014.02.016

Henderson, H. A. (2010). Electrophysiological correlates of cognitive control and the regulation of shyness in children. Developmental Neuropsychology, 35, 177-193. doi: $10.1080 / 87565640903526538$

Henderson, H. A., Pine, D. S., \& Fox, N. A. (2015). Behavioral inhibition and developmental risk: a dual-processing perspective. Neuropsychopharmacology, 40, 207. doi: 10.1038/npp.2014.189

Henderson, H. A., \& Wilson, M. J. (2017). Attention processes underlying risk and resilience in behaviorally inhibited children. Current Behavioral Neuroscience Reports, 4, 99-106. doi: 10.1007/s40473-017-0111-z

Karevold, E., Ystrom, E., Coplan, R. J., Sanson, A. V., \& Mathiesen, K. S. (2012). A prospective longitudinal study of shyness from infancy to adolescence: Stability, age-related changes, and prediction of socio-emotional functioning. Journal of Abnormal Child Psychology, 40, 11671177. doi: 10.1007/s10802-012-9635-6 
Ketelaars, M. P., Cuperus, J. M., van Daal, J., Jansonius, K., \& Verhoeven, L. (2009). Screening for pragmatic language impairment: The potential of the children's communication checklist. Research in Developmental Disabilities, 30, 952-960. doi: 10.1016/j.ridd.2009.01.006

Kim, O. H., \& Kaiser, A. P. (2000). Language characteristics of children with ADHD. Communication Disorders Quarterly, 21, 154-165. doi: 10.1177/152574010002100304

LaBounty, J., Bosse, L., Savicki, S., King, J., \& Eisenstat, S. (2017). Relationship between social cognition and temperament in preschool-aged children. Infant and Child Development, 26, e1981. doi: 10.1002/icd.1981

Leonard, M. A., Milich, R., \& Lorch, E. P. (2011). The role of pragmatic language use in mediating the relation between hyperactivity and inattention and social skills problems. Journal of Speech, Language, and Hearing Research, 54, 567 - 579. doi: 10.1044/1092-4388(2010/10-0058)

Levinson, S. C. (1983). Pragmatics. Cambridge: Cambridge University Press.

Lin, S., Keysar, B., \& Epley, N. (2010). Reflexively mindblind: Using theory of mind to interpret behavior requires effortful attention. Journal of Experimental Social Psychology, 46, 551-556. doi: 10.1016/j.jesp.2009.12.019

Liebermann, D., Giesbrecht, G. F., \& Müller, U. (2007). Cognitive and emotional aspects of selfregulation in preschoolers. Cognitive Development, 22, 511-529. doi: 10.1016/j.cogdev.2007.08.005

Lloyd, P., Mann, S., \& Peers, I. (1998). The growth of speaker and listener skills from five to eleven years. First Language, 18, 081-103. doi: 10.1177/014272379801805203

Mahone, E. M., \& Hoffman, J. (2007). Behavior ratings of executive function among preschoolers with ADHD. The Clinical Neuropsychologist, 21, 569-586. doi: 10.1080/13854040600762724 
Matthews, D., Biney, H., \& Abbot-Smith, K. (2018). Individual differences in children's pragmatic abilities: a review of associations with formal language, social cognition, and executive functions. Language Learning and Development, 14, 186-223. doi:

$10.1080 / 15475441.2018 .1455584$

McAuley, T., \& White, D. A. (2011). A latent variables examination of processing speed, response inhibition, and working memory during typical development. Journal of Experimental Child Psychology, 108, 453-468. doi: 10.1016/j.jecp.2010.08.009

Mewhort-Buist, T. A., \& Nilsen, E. S. (2013). What are you really saying? Associations between shyness and verbal irony comprehension. Infant and Child Development, 22(2), 180-197. doi: 10.1002/icd.1769

Mewhort-Buist, T. A., \& Nilsen, E. S. (2019). Shy children's understanding of irony: Better comprehension does not always mean better socioemotional functioning. Infant and Child Development, e2131. doi: 10.1002/icd.2131

Mink, D., Henning, A., \& Aschersleben, G. (2014). Infant shy temperament predicts preschoolers’ theory of mind. Infant Behavior and Development, 37, 66-75. doi: 10.1016/j.infbeh.2013.12.001

Miyake, A., Friedman, N. P., Emerson, M. J., Witzki, A. H., Howerter, A., \& Wager, T. D. (2000). The unity and diversity of executive functions and their contributions to complex "frontal lobe" tasks: A latent variable analysis. Cognitive Psychology, 41, 49-100. doi: 10.1006/cogp.1999.0734

Murphy, S. M., Faulkner, D. M., \& Farley, L. R. (2014). The behaviour of young children with social communication disorders during dyadic interaction with peers. Journal of Abnormal Child Psychology, 42, 277-289. doi: 10.1007/s10802-013-9772-6

Nelson, K. (2005). Language pathways into the community of minds. In J. W. Astington \& J. A. Baird (Eds.), Why language matters for theory of mind (pp. 26-49). Oxford University Press. 
Nilsen, E. S., \& Bacso, S. A. (2017). Cognitive and behavioural predictors of adolescents' communicative perspective-taking and social relationships. Journal of Adolescence, 56, 52-63. doi: 10.1016/j.adolescence.2017.01.004

Nilsen, E. S., \& Fecica, A. M. (2011). A model of communicative perspective-taking for typical and atypical populations of children. Developmental Review, 31, 55-78. doi: 10.1016/j.dr.2011.07.001

Nilsen, E. S., \& Graham, S. A. (2009). The relations between children's communicative perspectivetaking and executive functioning. Cognitive Psychology, 58, 220-249. doi: 10.1016/j.cogpsych.2008.07.002

Nilsen, E. S., Huyder, V., McAuley, T., \& Liebermann, D. (2017). Ratings of Everyday Executive Functioning (REEF): A parent-report measure of preschoolers' executive functioning skills. Psychological Assessment, 29, 50-64. doi: 10.1037/pas0000308

Nilsen, E. S., Varghese, A., Xu, Z., \& Fecica, A. (2015). Children with stronger executive functioning and fewer ADHD traits produce more effective referential statements. Cognitive Development, 36, 68-82. doi: 10.1016/j.cogdev.2015.09.001

Ninio, A., \& Snow, C. (1996). Pragmatic development. Boulder, CO: Westview Press.

O’Neill, D. K. (2007). The language use inventory for young children: A parent-report measure of pragmatic language development for 18-to 47-month-old children. Journal of Speech, Language, and Hearing Research, 50, 214 - 228. doi: 10.1044/1092-4388(2007/017)

Osborne, J. W., \& Overbay, A. (2004). The power of outliers (and why researchers should always check for them). Practical Assessment, Research, and Evaluation, 9(1), 6.

Osborne, J. W., \& Waters, E. (2002). Four assumptions of multiple regression that researchers should always test. Practical assessment, research, and evaluation, 8(1), 2. 
Parker, J., Rubin, K. H., Erath, S., Wojslawowicz, J. C., \& Buskirk, A. A. (2006). Peer relationships and developmental psychopathology. In D. Cicchetti, \& D. Cohen (Eds.), Developmental Psychopathology: Risk, disorder, and adaptation (2nd ed., Vol. 2, pp. 419e493). New York: Wiley.

Rints, A., McAuley, T., \& Nilsen, E. S. (2015). Social communication is predicted by inhibitory ability and ADHD traits in preschool-aged children: A mediation model. Journal of Attention Disorders, 19, 901-911. doi: 10.1177/1087054714558873

Roßnagel, C. (2000). Cognitive load and perspective-taking: applying the automatic-controlled distinction to verbal communication. European Journal of Social Psychology, 30, 429-445. doi: 10.1002/(SICI)1099-0992(200005/06)30:3<429::AID-EJSP3>3.0.CO;2-V

Rubin, K. H., Wojslawowicz, J. C., Rose-Krasnor, L., Booth-LaForce, C., \& Burgess, K. B. (2006). The best friendships of shy/withdrawn children: Prevalence, stability, and relationship quality. Journal of Abnormal Child Psychology, 34, 139-153. doi: 10.1007/s10802-005-9017-4

Russell, R. L., \& Grizzle, K. L. (2008). Assessing child and adolescent pragmatic language competencies: Toward evidence-based assessments. Clinical Child and Family Psychology Review, 11, 59-73. doi: 10.1007/s10567-008-0032-1

Spere, K. A., Schmidt, L. A., Theall-Honey, L. A., \& Martin-Chang, S. (2004). Expressive and receptive language skills of temperamentally shy preschoolers. Infant and Child Development: An International Journal of Research and Practice, 13, 123-133. doi: 10.1002/icd.345

Stroop, J. R. (1935). Studies of interference in serial verbal reactions. Journal of Experimental Psychology, 18, 643. doi: 10.1037/h0054651

Talwar, V., Murphy, S. M., \& Lee, K. (2007). White lie-telling in children for politeness purposes. International Journal of Behavioral Development, 31, 1-11. doi: 10.1177/0165025406073530 
Thorell, L. B., \& Nyberg, L. (2008). The Childhood Executive Functioning Inventory (CHEXI): A new rating instrument for parents and teachers. Developmental Neuropsychology, 33(4), 536-552. doi: $10.1080 / 87565640802101516$

Toplak, M. E., West, R. F., \& Stanovich, K. E. (2013). Practitioner review: Do performance-based measures and ratings of executive function assess the same construct? Journal of Child Psychology and Psychiatry, 54, 131-143. doi: 10.1111/jcpp.12001

Wardlow, L., \& Heyman, G. D. (2016). The roles of feedback and working memory in children's reference production. Journal of Experimental Child Psychology, 150, 180-193. doi: 10.1016/j.jecp.2016.05.016

Wechsler, D. (2001). Wechsler Individual Achievement Test - Second Edition (WIAT-II). San Antonio, TX: The Psychological Corporation.

White, L. K., McDermott, J. M., Degnan, K. A., Henderson, H. A., \& Fox, N. A. (2011). Behavioral inhibition and anxiety: The moderating roles of inhibitory control and attention shifting. Journal of Abnormal Child Psychology, 39, 735-747. doi: 10.1007/s10802-011-9490-x

Wright, I., Waterman, M., Prescott, H., \& Murdoch-Eaton, D. (2003). A new Stroop-like measure of inhibitory function development: Typical developmental trends. Journal of Child Psychology and Psychiatry, 44, 561-575. doi: 10.1111/1469-7610.00145

Zajączkowska, M., \& Abbot-Smith, K. (accepted). “Sure I'll Help - I've just been sitting around doing nothing at school all day": cognitive flexibility and child irony interpretation. Journal of Experimental Child Psychology. 
Table 1

Descriptive Statistics for Measures of Executive Functioning (EF), Pragmatic Abilities and Shyness

\begin{tabular}{|c|c|c|c|c|}
\hline Variable & $M$ & $S D$ & Minimum & Maximum \\
\hline Age (in months) & 113.87 & 10.64 & 99.50 & 132.93 \\
\hline $\begin{array}{l}\text { Parent-reported EF } \\
\text { (CHEXI WM / IC composite) }\end{array}$ & 34.10 & 9.72 & 16.00 & 61.00 \\
\hline $\begin{array}{l}\text { Working Memory (WM) } \\
\text { (Digit Span Backwards) }\end{array}$ & 6.48 & 1.52 & 3.00 & 10.00 \\
\hline $\begin{array}{l}\text { Inhibitory Control (IC) } \\
\text { (Color-Word Interference) }\end{array}$ & -.49 & 17.65 & -33.66 & 57.54 \\
\hline $\begin{array}{l}\text { Pragmatic knowledge } \\
\text { (CASL Pragmatic Judgment score) }\end{array}$ & 52.55 & 8.02 & 26.00 & 68.00 \\
\hline $\begin{array}{l}\text { Parent-reported pragmatic ability } \\
\text { (CCC-2 Pragmatic composite) }\end{array}$ & 10.41 & 9.09 & .00 & 44.99 \\
\hline Shyness (CSQ) & 21.16 & 9.52 & 2.00 & 49.64 \\
\hline
\end{tabular}

Note. Higher scores on IC, CHEXI and CCC-2 reflect weaker skills. 


\section{Table 2}

Bivariate and Partial Correlations between Age, Gender, Measures of Executive Functioning (EF), Shyness, and Pragmatic Ability

\begin{tabular}{|c|c|c|c|c|c|c|c|}
\hline & Gender & $\begin{array}{c}\text { Parent- } \\
\text { reported EF }\end{array}$ & $\begin{array}{l}\text { Working } \\
\text { memory } \\
(\mathrm{WM})\end{array}$ & $\begin{array}{c}\text { Inhibitory } \\
\text { control (IC) }\end{array}$ & $\begin{array}{l}\text { Pragmatic } \\
\text { Knowledge }\end{array}$ & $\begin{array}{l}\text { Parent- } \\
\text { reported } \\
\text { Pragmatic } \\
\text { Ability }\end{array}$ & Shyness \\
\hline & $\begin{array}{l}\text { Male }(0) \text { or } \\
\text { Female (1) }\end{array}$ & CHEXI & $\begin{array}{l}\text { Backward } \\
\text { Digit Span }\end{array}$ & $\begin{array}{c}\text { Residual } \\
\text { Color-Word } \\
\text { Interference }\end{array}$ & CASL & CCC-2 & CSQ \\
\hline CHEXI & $-.32 * *$ & 1 & - & - & - & - & - \\
\hline WM & $.29 * *$ & $-.12(.04)$ & 1 & - & - & - & - \\
\hline IC & -.09 & $.17(.16)$ & $.06(.15)$ & 1 & - & - & - \\
\hline CASL & $.19^{\mathrm{t}}$ & $-.24 *(-.14)$ & $.25^{*}(.08)$ & $-.32 * *(-.27 *)$ & 1 & - & - \\
\hline CCC-2 & $-.32 * *$ & $.53^{* *}\left(.45^{* *}\right)$ & $-.11(.06)$ & $.02(-.02)$ & $-.21^{\mathrm{t}}(-.12)$ & 1 & - \\
\hline CSQ & .02 & $.004(.05)$ & $-.04(.03)$ & $.07(.06)$ & $-.24 *\left(-.21^{t}\right)$ & $.03(-.003)$ & 1 \\
\hline Age & .01 & -.11 & $.31 * *$ & -.18 & $.42 * *$ & -.15 & -.13 \\
\hline
\end{tabular}

Note. Partial correlations controlling for age and gender are shown in the parentheses. Color-Word Interference scores reflect completion time. Higher scores on IC, CHEXI, and CCC-2 reflect weaker skills.

${ }^{\mathrm{t}} p<.09, * p<.05, * * p<.01$ 


\section{Table 3}

Regression of Children's Pragmatic Knowledge (i.e., CASL Pragmatic Judgment Score)

\begin{tabular}{|c|c|c|c|c|c|c|c|c|c|c|c|c|c|}
\hline \multirow{2}{*}{\multicolumn{2}{|c|}{ Step }} & \multicolumn{4}{|c|}{ Step 1} & \multicolumn{4}{|c|}{ Step 2} & \multicolumn{4}{|c|}{ Step 3} \\
\hline & & \multirow{2}{*}{$\begin{array}{c}B \\
.32\end{array}$} & \multirow{2}{*}{$\begin{array}{l}S E \\
.08\end{array}$} & \multirow{2}{*}{$\begin{array}{c}t \\
4.15\end{array}$} & \multirow{2}{*}{$\begin{array}{c}p \\
<.001\end{array}$} & \multirow{2}{*}{$\begin{array}{c}B \\
.23\end{array}$} & \multirow{2}{*}{$\begin{array}{l}S E \\
.08\end{array}$} & \multirow{2}{*}{$\begin{array}{c}t \\
2.90\end{array}$} & \multirow{2}{*}{$\begin{array}{c}p \\
.005\end{array}$} & \multirow{2}{*}{$\begin{array}{l}B \\
.22\end{array}$} & \multirow{2}{*}{$\begin{array}{l}S E \\
.08\end{array}$} & \multirow{2}{*}{$\begin{array}{c}t \\
2.79\end{array}$} & \multirow{2}{*}{$\begin{array}{c}p \\
.007\end{array}$} \\
\hline 1 & Age (in months) & & & & & & & & & & & & \\
\hline 1 & Gender $(0=$ male, $1=$ female $)$ & 3.16 & 1.64 & 1.93 & .06 & 1.70 & 1.70 & 1.00 & .32 & 1.42 & 1.68 & .85 & .40 \\
\hline 2 & Shyness (CSQ) & & & & & -.17 & .08 & -2.04 & .05 & -.20 & .08 & -2.44 & .02 \\
\hline 2 & Digit Span Backward (WM) & & & & & .72 & .56 & 1.28 & .20 & .79 & .56 & 1.43 & .16 \\
\hline 2 & Color-Word Interference (IC) & & & & & -.10 & .05 & -2.22 & .03 & -.10 & .05 & -2.19 & .03 \\
\hline 2 & Parent reported EF (CHEXI) & & & & & -.11 & .09 & -1.26 & .21 & -.18 & .09 & -1.94 & .06 \\
\hline 3 & Shyness x CHEXI & & & & & & & & & -.02 & .01 & -1.95 & .05 \\
\hline & Model & $R^{2}=$ & $\begin{array}{l}F \\
p\end{array}$ & $\begin{array}{l}7)= \\
1\end{array}$ & & & & & & & & & \\
\hline & Model Change & & & & & \multicolumn{4}{|c|}{$\begin{array}{c}\Delta R^{2}=.12, \Delta F(4,73)=3.23 \\
p=.02\end{array}$} & \multicolumn{4}{|c|}{$\begin{array}{c}\Delta R^{2}=.03, \Delta F(1,72)=3.83, \\
p=.05\end{array}$} \\
\hline
\end{tabular}

Note. Higher scores on IC and CHEXI reflect weaker abilities. 


\section{Table 4}

Regression of Children's Parent-reported Pragmatic Abilities (i.e., CCC-2 Pragmatic Composite)

\begin{tabular}{|c|c|c|c|c|c|c|c|c|c|c|c|c|c|}
\hline \multirow{2}{*}{\multicolumn{2}{|c|}{ Step }} & \multicolumn{4}{|c|}{ Step 1} & \multicolumn{4}{|c|}{ Step 2} & \multicolumn{4}{|c|}{ Step 3} \\
\hline & & \multirow{2}{*}{$\begin{array}{l}B \\
-.20\end{array}$} & \multirow{2}{*}{$\begin{array}{c}S E \\
.07\end{array}$} & \multirow{2}{*}{$\frac{t}{-2.92}$} & \multirow{2}{*}{$\frac{p}{.005}$} & \multirow{2}{*}{$\frac{B}{-.15}$} & \multirow{2}{*}{$\begin{array}{r}S E \\
.07\end{array}$} & \multirow{2}{*}{$\begin{array}{c}t \\
-2.26\end{array}$} & \multirow{2}{*}{$\begin{array}{l}p \\
.03\end{array}$} & \multirow{2}{*}{$\frac{B}{-.14}$} & \multirow{2}{*}{$\begin{array}{c}S E \\
.06\end{array}$} & \multirow{2}{*}{$\frac{t}{-2.22}$} & \multirow{2}{*}{$\begin{array}{c}p \\
.03\end{array}$} \\
\hline 1 & Age (in months) & & & & & & & & & & & & \\
\hline 1 & Gender $(0=$ male, $1=$ female $)$ & -5.60 & 1.49 & -3.77 & $<.001$ & -3.17 & 1.44 & -2.21 & .03 & -2.52 & 1.39 & -1.82 & .07 \\
\hline 2 & Shyness (CSQ) & & & & & .06 & .07 & .82 & .41 & .10 & .07 & 1.44 & .15 \\
\hline 2 & Digit Span Backward (WM) & & & & & -.44 & .48 & -.92 & .36 & -.51 & .46 & -1.10 & .27 \\
\hline 2 & Color-Word Interference (IC) & & & & & -.04 & .04 & -.95 & .35 & -.04 & .04 & -1.01 & .32 \\
\hline 2 & Parent reported EF (CHEXI) & & & & & .38 & .08 & 5.01 & $<.001$ & .45 & .08 & 5.92 & $<.001$ \\
\hline 3 & Shyness x CHEXI & & & & & & & & & .02 & .008 & 2.88 & .005 \\
\hline & Model & $R^{2}=.2$ & $\begin{array}{l}F(2 \\
<\end{array}$ & $=1$ & & \multirow{2}{*}{\multicolumn{4}{|c|}{$\begin{array}{c}\Delta R^{2}=.21, \Delta F(4,71)=6.63 \\
p<.001\end{array}$}} & \multirow{2}{*}{\multicolumn{4}{|c|}{$\begin{array}{c}\Delta R^{2}=.06, \Delta F(1,70)=8.31 \\
p=.005\end{array}$}} \\
\hline & Model Change & & & & & & & & & & & & \\
\hline
\end{tabular}

Note. Higher scores on IC and CHEXI reflect weaker abilities. 


\section{Figure Captions}

\section{Figure 1}

Interaction between shyness (CSQ) and parent-reported EF (CHEXI) in predicting pragmatic knowledge (CASL Pragmatic Judgement score). Higher scores on the CHEXI reflect weaker skills.

Figure 2

Interaction between shyness $(C S Q)$ and parent-reported EF (CHEXI) in predicting parentreported pragmatic ability (CCC-2 Pragmatic composite.) Higher scores on the CHEXI and CCC-2 reflect weaker skills. 